\title{
Towards safe and efficient cervical dilatation
}

\author{
Avinoam Tzabari ${ }^{1,2}$, Amnon Weichselbaum ${ }^{3}$, Michael Stark ${ }^{1,4,5}$ \\ ${ }^{1}$ New European Surgical Academy, Berlin 10117, Germany. \\ ${ }^{2}$ Yoseftal Medical Center, Eilat 88000, Israel. \\ ${ }^{3}$ NTG Technological Incubator, Nazareth 16001, Israel. \\ ${ }^{4}$ ELSAN Hospital Group, Paris 75008, France. \\ ${ }^{5}$ Charite University Hospital, Berlin 10117, Germany.
}

Correspondence to: Dr. Michael Stark, New European Surgical Academy, Unter den Linden 21, Berlin 10117, Germany.

E-mail:mstark@nesacademy.org

How to cite this article: Tzabari A, Weichselbaum A, Stark M. Towards safe and efficient cervical dilatation. Mini-invasive Surg 2018;2:9. https://doi.org/10.20517/2574-1225.2018.11

Received: 2 Mar 2018 First Decision: 3 Apr 2018 Revised: 12 Apr 2018 Accepted: 13 Apr 2018 Published: 27 Apr 2018

Science Editor: Simone Ferrero, Atef Darwish Copy Editor: Jun-Yao Li Production Editor: Huan-Liang Wu

\begin{abstract}
Aim: Traditional methods of cervical dilatation such as Hegar rods and laminaria are associated with the damage leading to the risk of cervical incompetence or require two sessions with higher risk of infections. In this study, a new dilator based on expanding triple balloons is assessed.
\end{abstract}

Methods: Cervical dilation with the triple balloon was evaluated in 15 women with various indications. After measuring the diameter of the cervix the triple balloon was inserted and inflated for 5-7 min and thereafter measured again.

Results: This time was sufficient to achieve the diameter of 4.5-9.5 mm which allowed performing all planned procedures without any need for further dilatation except for one case with cervical stenosis.

Conclusion: Further studies are needed, but the triple dilating balloon might become the optimal dilatation method for universal use.

Keywords: Cervical dilatation, hysteroscopy, abortion

\section{INTRODUCTION}

The Muellerian ducts are being formed from the paramesonephric cells and are creating the uterine body and the cervix. The endometrium has its unique, hormonally dependent cyclic pattern and the cervical mucous layer shows different cyclic characteristics ${ }^{[1]}$. Despite the common origin of the different elements of

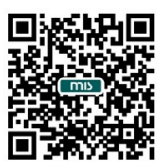


the uterus, their tissue architecture is different: smooth muscle in the lower third of the cervix is $6.4 \%, 18 \%$ in the middle third and $28.8 \%$ in the upper third, in the body of the uterus it is $68.8 \%^{[2]}$. The muscle tissue of the uterus is different from other striated muscles in the body. It is retractile, which means that it is able to rest while being contracted ${ }^{[3]}$. The cervix does not function as other sphincters in the body and expands passively and gradually as it is a fibrous organ which contains hyaluronic acid, collagen and proteoglycan ${ }^{[4]}$.

Most intrauterine procedures need dilatation of the cervix in order to be able to introduce optical or surgical devices. As most of the cervix is composed of fibrous tissue and just small part of it is muscle, dilatation of the cervix without being originally primed by hormones as is the case during delivery, is certainly a nonphysiological process. Therefore it is common that cervical dilatation by itself is associated with crucial pain if anesthesia is not used and involves the risk of the cervical incompetence in the future ${ }^{[5]}$.

The cervical incompetence as the result of dilatation with Hegar rods and curettage is likely to be due to the damage occurring from the stretching of fibrous tissues of the cervix in two directions (longitudinal and transverse) ${ }^{[6]}$.

Using laminaria causes only tranverse streching of the tissues and the dilatation occurs gradually over several hours. Gradual dilatation and softening of the dilating cervix reduce the risk of injuries and perforation ${ }^{[7]}$; anesthesia is not needed, however two sessions are mandatory for insertion and removal and dilation procedure takes several hours.

Both Hegar rods and laminaria have been in use for many years for dilatation. Recently, a new method was introduced. It is a $3-\mathrm{mm}$ diameter triple balloon which is easily inserted into the uterus, anchored; and the two dilating balloons are inflated with saline creating lateral pressure of up to 6 bars which results in gradual dilatation of the cervix up to 8-9 $\mathrm{mm}$ within 5-7 min. The method is less painful and anesthesia usually is not needed unless surgical procedures are planned.

\section{METHODS}

\section{Subject selection}

The study included 15 women undergoing termination of pregnancy for different indications.

\section{Inclusion criteria}

1. Females with 18 years of age or older;

2. Subjects undergoing termination of pregnancy;

3. Subjects willing to sign informed consent form.

\section{Exclusion criteria}

1. Subjects younger than 18 years of age;

2. Subjects unwilling or unable to sign the informed consent form.

\section{Description}

The device is compound of three balloons and a catheter. The distal balloon anchors the device in its place beyond the internal Os. Two elongated dilating balloons are designed in order to enable efficient dilation of any cervices ranging in length from 3 to $7 \mathrm{~cm}$. The outer diameter of the deflated semi-rigid catheter is 7 French $(2.3 \mathrm{~mm})$, enabling easy insertion of the catheter in the cervical canal. Prior to the dilation, the dimeter of the cervix is measured with calibrated Hegar rods.

The catheter with deflated balloons [Figure 1] is inserted through the cervix into the uterus. An anchoring balloon is inflated through the "anchor channel" [Figure 1] with $2.5 \mathrm{~mL}$ syringe with $1.5 \mathrm{~mL}$ of saline 


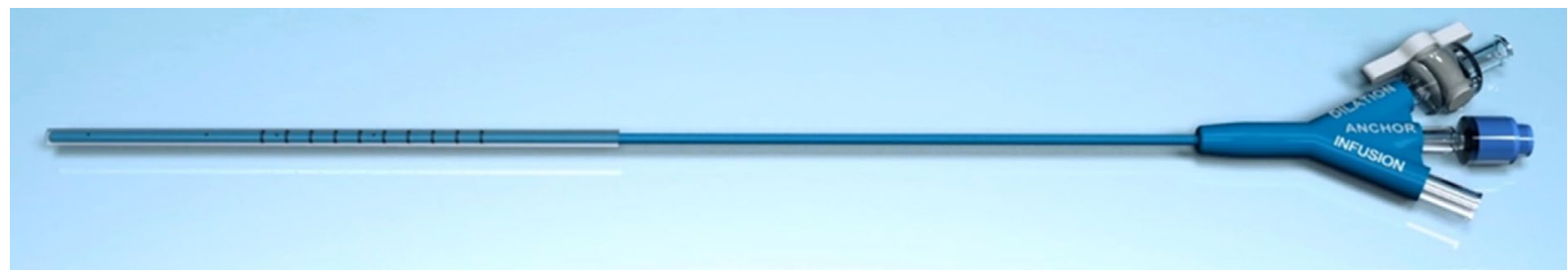

Figure 1. The triple balloon catheter - deflated balloons (cited from Weichselbaum and Stark ${ }^{[6]}$ with permission)

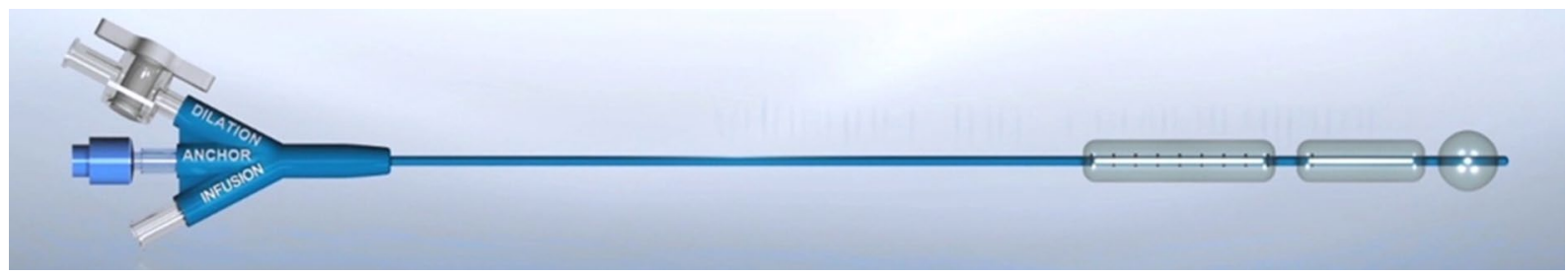

Figure 2. The triple-balloon catheter - inflated balloons (frontal anchor balloons and two elongated dilating balloons) (cited from Weichselbaum and Stark ${ }^{[6]}$ with permission)

solution. Both elongated dilating balloons are then inflated simultaneously at each end of the cervical canal (internal and external Os) by injections of $2.5 \mathrm{~mL}$ saline through the "dilation channel". The surgeon can control the inflation rate and dilate the cervix gradually according to the resistance created. The inflation of the dilating balloon takes around $10 \mathrm{~s}$, and the inflated balloons stay in the cervical canal up to $7 \mathrm{~min}$ depending on the needed diameter [Figure 2]. In the next stage, saline solution is injected into the cervical canal between the two dilating balloons through the "infusion channel" for washing and lubricating of the cervix. For catheter removal, the balloons are deflated. For the final cervical diameter assessment, the cervix is measured again by calibrated Hegar rods.

The device was used in 15 women at the Yoseftal Hospital in Eilat, Israel in patients where dilatation of the cervix was indicated for various procedures. The study was approved by the Hospital Ethical Committee and all participants signed informed consent form. The aim of the study was to find out if the triple balloon catheter could be a valid alternative to the traditional dilatation with Hegar rods.

Procedure started with patients in lithotomy position, thorough cleaning of the vulva and the vagina. After the patient was covered, speculum was inserted, the upper part of the cervix was grasped with tenaculum forceps and the diameter of the cervix was measured with calibrated Hegar rods. The triple balloon catheter was thereafter inserted into the cervix without difficulties except one case where cervical stenosis did not enable its insertion. The anchor balloon was inflated and the catheter was gently pulled out until it was fixed in the optimal position and thereafter the two elongated dilating balloons were inflated and left in situ for 5-7 min. The cervix was lubricated with saline solution between both dilating balloons and then the catheter was removed and the diameter of the dilated cervix was measured again with calibrated Hegar rods.

\section{RESULTS}

The details of the clinical outcome are summarized in Table 1 . The average age of the patients was 29.1 years. The minimal diameter of the cervix prior to the dilatation was $2 \mathrm{~mm}$ and the maximal was $4.5 \mathrm{~mm}$. After the dilatation with the balloon catheter, the minimal diameter of the cervix was measured as $4.5 \mathrm{~mm}$ and the maximal was $9.5 \mathrm{~mm}$. With the exception of one case which was clinically diagnosed as cervical stenosis, all the needed intrauterine procedures were done without any need for additional dilatation with other methods. 
Table 1. Outcome of cervical dilatation with triple catheter in 15 cases

\begin{tabular}{|c|c|c|c|c|}
\hline \multirow{2}{*}{ Case } & \multirow{2}{*}{ Age, years } & \multirow{2}{*}{$\begin{array}{l}\text { G (gravity), } \\
\text { D (delivery) }\end{array}$} & \multicolumn{2}{|c|}{ Cervix diameter } \\
\hline & & & Before dilatation & After dilatation \\
\hline 1 & 33 & G1D0 & 4 & 9 \\
\hline 2 & 25 & G1D0 & 4 & 8 \\
\hline 3 & 18 & G1D0 & 4.5 & 8 \\
\hline 4 & 20 & G1D0 & 2.5 & Cervix stenosis \\
\hline 5 & 19 & G1D0 & 3 & 7 \\
\hline 6 & 21 & G1D0 & 3.5 & 8 \\
\hline 7 & 24 & G2D0 & 3 & 8 \\
\hline 8 & 38 & G4D3 & 3 & 5.5 \\
\hline 9 & 42 & G3D2 & 4 & 9 \\
\hline 10 & 32 & G1D0 & 2.5 & 9.5 \\
\hline 11 & 42 & G3D2 & 4 & 9 \\
\hline 12 & 27 & G1D0 & 3.5 & 9 \\
\hline 13 & 37 & G4D4 & 2 & 4.5 \\
\hline 14 & 29 & G6D5 & 2 & 5 \\
\hline 15 & 30 & G3D2 & 2.5 & 5.5 \\
\hline
\end{tabular}

\section{DISCUSSION}

Cervical dilatation with Hegar rods is used all-over the world however with the risk of future cervical incompetence which is higher in nulliparous. During the dilation with Hegar rods, the cervix is stretched in two different directions, longitudinal and radial, which can be damaging because the cervix consists of mainly fibrous tissue and collagen although the percentage of collagen varies with cervical pathologies ${ }^{[8]}$. This is in contrast to the body of the uterus where the percentage of the muscular tissue is significantly higher than in the cervix ${ }^{[6]}$. The balloon catheter has the advantage over Hegar rods because it does not stretch the cervical walls longitudinally, and so minimizing or eliminating the risk of the damage to the cervical tissue.

Laminaria is associated with lower risk of damage to the cervical wall but the balloon catheter has advantage over it because desired dilatation can be achieved in several minutes versus hours and two sittings needed when laminaria is used.

Dilating balloons allowed to successfully dilate the cervix to the desired diameter in all cases except the diagnosed cervical stenosis and the dilatation was sufficient for all the planned procedures. No vasovagal attack incidence was recorded during the study.

A novel method to dilate the cervix whenever it is indicated is presented. The balloon catheter proved to be user-friendly, efficient and is not associated with risks of damage to the cervical wall and potential cervical incompetence.

This pilot study shows that the balloon catheter is a promising method but more studies will be needed in order to prove its efficiency and its potential for universal use for any indication of cervical dilatation.

\section{DECLARATIONS}

\section{Authors' contributions}

Manuscript preparation and data acquisition: Stark M

Literature search: Stark M

Surgery: Tzabari A

Data acquisition: Tzabari A

Study design and definition of intellectual content: Weichselbaum A 


\section{Financial support and sponsorship}

None.

\section{Conflicts of interest}

There are no conflicts of interest.

\section{Patient consent}

All participants signed informed consent form.

\section{Ethics approval}

The study was approved by the Hospital Ethical Committee.

\section{Copyright}

(C) The Author(s) 2018.

\section{REFERENCES}

1. Fluhmann CF. The developmental anatomy of the cervix uteri. Obstet Gynecol 1960;15:62-9.

2. Rorie DK, Newton, M. Histologic and chemical studies of the smooth muscle in the human cervix and uterus. Amer J Obst Gynec 1967;99:466-9

3. Tinelli A, Malvasi A, Cavallotti C, Dell'Edera D, Tsin DA, Stark M, Mettler L. The management of fibroids based on immunohistochemical studies of their pseudocapsules. Expert Opin Ther Targets 2011;15:1241-7.

4. Kavanagh J, Kelly AJ, Thomas J. Hyaluronidase for cervical ripening and induction of labour. Cochrane Database Syst Rev 2006;(2):CD003097.

5. Roman A, Suhag A, Berghella V. Overview of cervical insufficiency: diagnosis, etiologies, and risk factors. Clin Obstet Gynecol 2016;59:237-40

6. Weichselbaum A, Stark M. Uterine cervix dilatation based on new insights of embryology - method description. Obstet Gynecol Rep 2017;1:1-3.

7. Lichtenberg ES. Complications of osmotic dilators. Obstet Gynecol Surv 2004;59:528-36.

8. Sundtoft I, Langhoff-Roos J, Sandager P, Sommer S, Uldbjerg N. Cervical collagen is reduced in non-pregnant women with a history of cervical insufficiency and a short cervix. Acta Obstet Gynecol Scand 2017;96:984-90. 